\title{
THE EFFECTIVENESS OF INTERFERON BETA-1A IN MANAGEMENT OF MULTIPLE SCLEROSIS: A CASE REPORT
}

\author{
Vivien Puspitasari ${ }^{1,2}$, Anyeliria Sutanto ${ }^{1,2}$, Aristo Pangestu ${ }^{1}$ \\ Correspondence: vivien.puspitasari@uph.edu \\ ${ }^{1}$ Faculty of Medicine Universitas Pelita Harapan, Bencongan, Kelapa Dua, Tangerang, Banten, Indonesia \\ ${ }^{2}$ Siloam Hospitals Lippo Village, Bencongan, Kelapa Dua, Tangerang, Banten, Indonesia
}

\author{
Article History: \\ Received: September 5, 2019 \\ Accepted: June 25, 2020 \\ Published: July 1, 2020

\section{Cite this as:} \\ Puspitasari V, Sutanto A, \\ Pangestu A. The effectiveness of \\ interferon beta-la in management \\ of multiple sclerosis: a case \\ report. Malang Neurology \\ Journal; 2020.6:98-104. \\ http://dx.doi.org/10.21776/ub.mnj \\ .2020 .006 .02 .10
}

\section{ABSTRACT}

\begin{abstract}
Multiple sclerosis is a chronic autoimmune disease that attacks myelin in the central nervous system. About 2.5 million people worldwide have been diagnosed with multiple sclerosis. Its clinical presentation could varies according to the location of the lesion. Interferon beta is the most commonly used as immunomodulation therapy. However, its effectiveness for long-term use is still questionable. We report a case of 24-year-old woman with complaint of ataxia and limb weakness which were diagnosed as multiple sclerosis relapsing remitting (MSRR) and treated with interferon beta 1a for five years. During routine interferon beta 1a treatment three times a week, patient has still experienced four episodes of relapse in spite of good compliance. Hence, the rare presence of neutralizing antibody was suspected. It commonly occur after a year of interferon theraphy, which is consistent with the patient's treatment history. Further biomarker testing of drug-specific antibodies might be valuable to find out the possibility of interferon resistance
\end{abstract}

Keywords: Autoimmune, demyelinitation, interferon beta, multiple sclerosis

\section{Introduction}

Multiple sclerosis (MS) is a major cause of non-traumatic neurologic disability experienced by nearly 2.5 million people worldwide. Based on research results from Atlas of MS, the number of multiple sclerosis patients worldwide increased from 2.1 million in 2008 to 2.3 million in $2013 .{ }^{1}$ There is no epidemiological data of multiple sclerosis in Indonesia, but epidemiological study in Southeast Asia show the estimated prevalence of MS is $0-5$ per $100,000 .{ }^{2}$

Multiple sclerosis is a chronic condition characterized clinically by episodes of focal disorders of the optic nerve, spinal cord, and brain, which can undergo varying degrees of remission, and relapse in months or years, and are generally progressive. Multiple diagnosis of sclerosis is made by using the McDonald's criteria. The commonly used investigation is Magnetic Resonance Imaging (MRI) and cerebrospinal fluid analysis which show oligoclonal bands. $^{3}$

Management of multiple sclerosis aims to prevent relapse, accelerate recovery, inhibit progression, and overcome symptoms. Commonly used therapeutic agents are antiinflammatory and immunomodulator, such as interferon beta, glatiramer acetate, fingolimod, and teriflunomide. Interferon beta 1a is an immunomodulator, which is most often used in the management of multiple sclerosis due to its high effectiveness and availability, as well as minimal side effects. The emergence of neutralizing antibodies is a major problem in the use of interferon beta $1 \mathrm{a} .{ }^{4}$ Several studies have shown that neutralizing antibodies can worsen the symptoms of relapse, disease progression, and MRI lesions. Based on studies which were conducted by Boz, the relapse rate in patients with positive neutralizing antibody were significantly greater than in patients with negative neutralizing antibody during three years treatment. ${ }^{5}$ Tomassini's research showed that patients with positive $\mathrm{NAb}$ were more at risk of developing disabilities within 5 years of treatment. ${ }^{6}$ From several studies conducted in Europe, MRI lesions in patients with positive NAb were wider compared with patients with negative NAb. High antibody titers reduce the biological response of interferon to target receptors in cells. In the case of low or medium titers, the effect of neutralizing antibodies is not known with certainty because in some cases there is an increase in the rate of relapse, but in other cases there is a decrease in relapse rates. ${ }^{7}$

\section{Case Report}

A 24-year-old woman came to neurology clinic with complaints of ataxia for four months in episodic course. Each episode of symptoms lasts about five days to a week, followed by symptom improvement. The examination of balance and coordination found ataxia, dysdiadokokinesia, dysmetria, accompanied by wide based gait, along with mild spasticity on all extremities. Brain MRI with contrast showed multiple sclerotic pathological lesions scattered in 
Before treatment

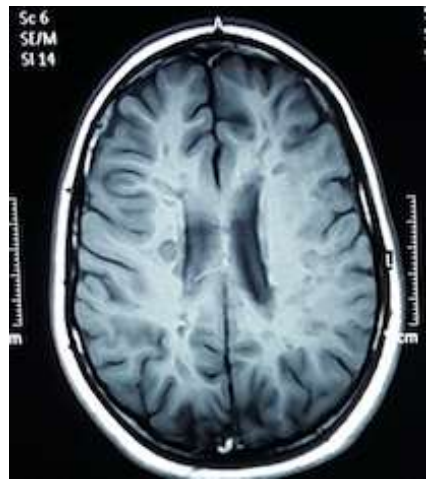

(a)

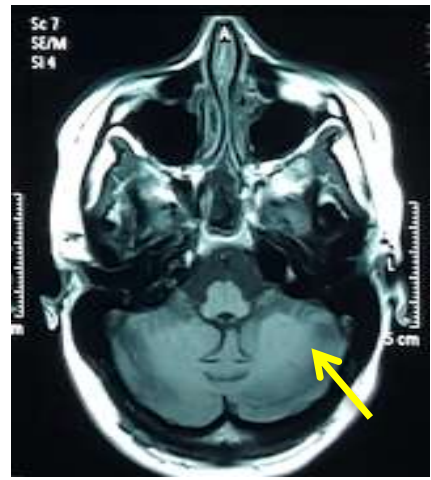

(c)

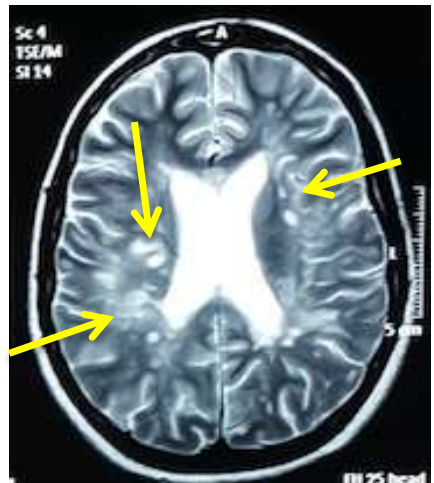

(b)

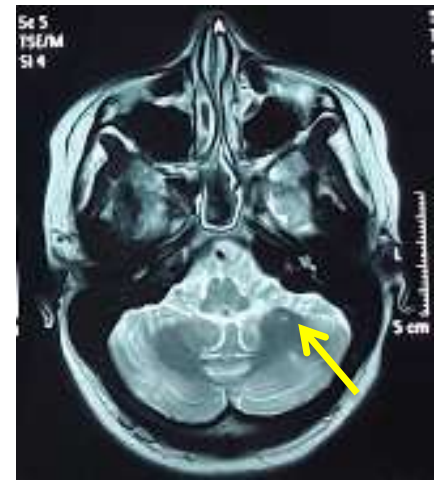

(d)

After treatment

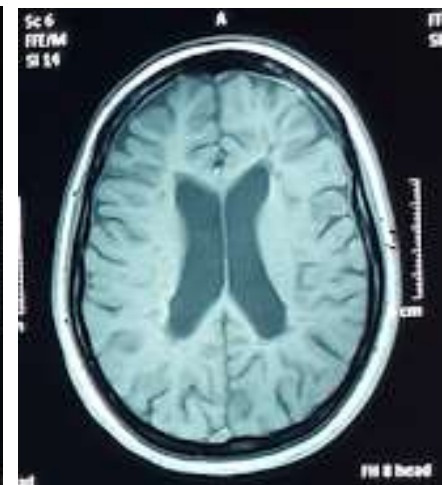

(e)

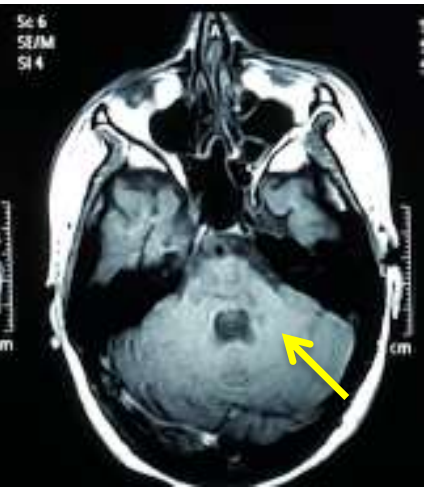

(g)

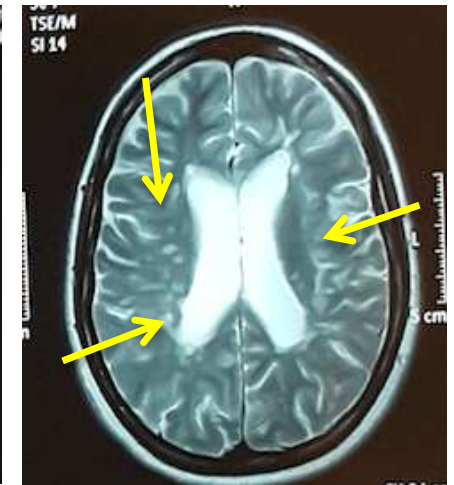

(f)

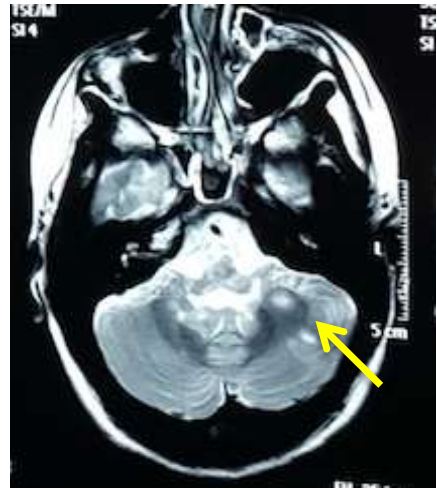

(h)

Figure 1. Non-contrast head MRI before treatment: (a) T1WI axial and (b) T2 WI axial slices show multiple bilateral periventricular and subcortical lesions, (c) T1 WI axial and (d) T2 WI axial slices show multiple lesion in left cerebellum hemisphere. Non-contrast head MRI after treatment: (e) T1 WI axial and (f) T2 WI axial slices show multiple bilateral periventricular and subcortical lesions, (g) T1 WI axial and (h) T2 WI axial show multiple lesion in left cerebellum hemisphere

Before treatment

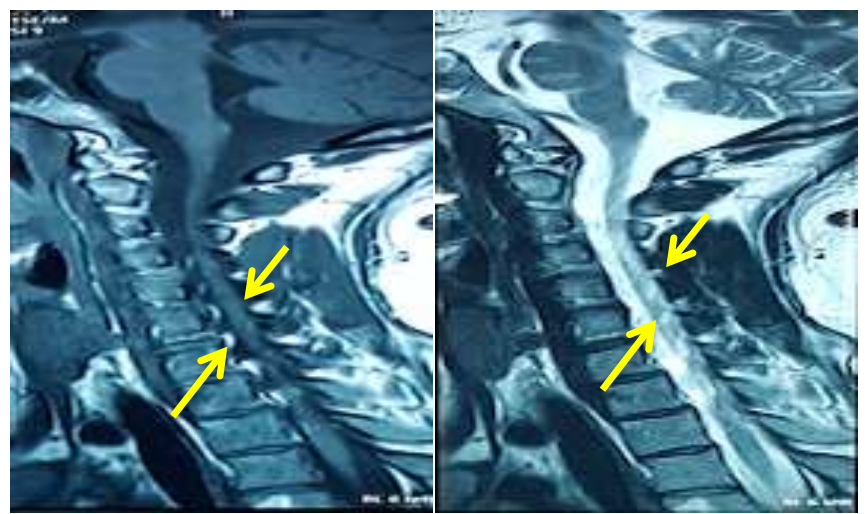

(a) (b)
After treatment

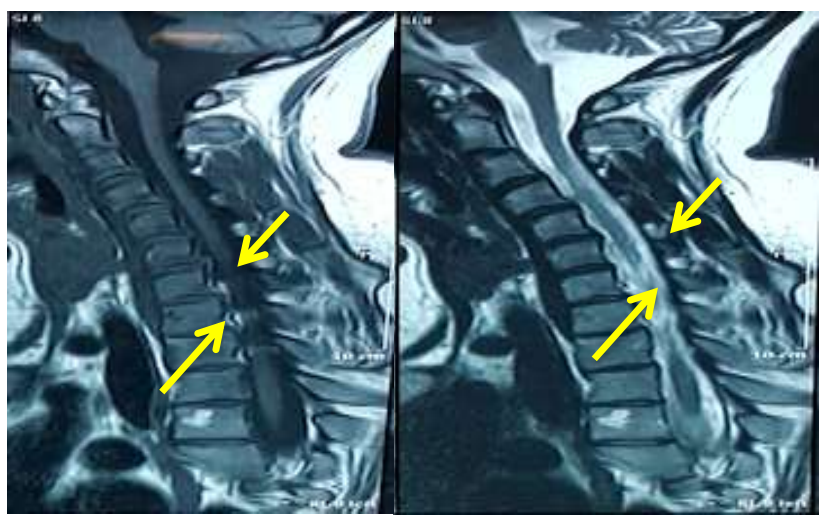

(c)

(d)

Figure 2. Non-contrast cervical MRI before treatment: (a)T1 WI sagittal and (b) T2 WI sagittal slices show intramedullary pathological intensity lesions scattered throughout the cervical segment of the spinal cord (pointed by yellow arrow). Non-contrast cervical MRI after treatment: both (c) T1 WI sagittal and (d) T2 WI sagittal slices doesn't show significant changes compared to the previous MRI. 
bilateral lateral periventricular white substances with Dawson finger and juxtacortical images of both cerebral hemispheres. Non-contrast cervical MRI showed the presence of pathological intensity lesions in the spinal cord as high as C3-C4 and C5-C6. Examination of cerebrospinal fluid analysis showed a positive oligoclonal band.

The patient has been diagnosed with multiple sclerosis and started to receive interferon beta $1 \mathrm{a}$, given by subcutaneous injection $44 \mathrm{mcg}$ three times a week. For each episode of acute relapse, the patient is given intravenous methylprednisolone ( 1 gram daily) for 5 days, followed by an oral prednisone taper $(1 \mathrm{mg} / \mathrm{kg} / \mathrm{day}$ for one week, with rapid reduction over the ensuing 1-2 weeks). During routine treatment within 5 years, the patient has relapsed for four times with same symptoms. Each symptom appeared for 1 to 2 weeks and then experienced a remission with corticosteroid treatment. Patients routinely undergo interferon theraphy and deny ever changing to another type of interferon theraphy. During the treatment period the patient has never been tested for neutralizing antibodies. At the most recent episode of relapse she got worsen and had walking difficulty. Neurological examination revealed ataxia and mild spastic paralysis on her four extremities. Brain and cervical MRI evaluation was done and showed progressive brain lesion which was worsened compared to 5 years ago. It showed multiple lesions with pathological intensity, non-contrast enhancing in bilateral frontal, parietal, temporal, occipital, thalamus, basal ganglia, corpus callosum, left cerebral pedunculus, pons, left cerebellum hemispheres and medulla oblongata (Figure 1). It was also showed a pathological lesion of the intramedullary scattered throughout the cervical segment of the cervical spine to the level of the thoracic segment three (Figure 2).

\section{Discussion}

Multiple sclerosis is a major cause of non-traumatic neurological functional disorder. The cause of multiple sclerosis is still not known with certainty, but suspected interaction between genetic and environmental factors have major role in multiple sclerosis. Multiple sclerosis symptoms generally begins with symptoms due to lesions in the optic nerve, spinal cord, or brain stem with cognitive impairment as symptoms at the end of the course of the disease. ${ }^{4}$ Based on data from the Atlas of Multiple sclerosis, the most common initial symptoms in patients with multiple sclerosis are sensory disorders (49\%), motor disorders (39\%), visual disturbances (30\%), fatigue (30\%), balance disorders (24\%), sexual function disorders $(20 \%)$, urinary disorders $(17 \%)$, pain $(15 \%)$, and cognitive disorders $(10 \%){ }^{8}$ Diagnosis is generally difficult to made at the onset of the course of the disease, where signs and symptoms show only one focus on the central nervous system. Furthermore, in the course of the disease in which there are remissions and relapses accompanied by wider dissemination throughout the central nervous system, multiple diagnosis of sclerosis is more certain. The course of the disease from multiple may vary. In the relapseremitting type, signs and symptoms are improved or even fully recovered, followed by symptom-free intervals and may subsequently recur in the same neurologic abnormality or new symptoms suggesting a new focus on the central nervous system. Less than half of cases of multiple sclerosis, have a progressive course, generally in patients over the age of 40, are known as primary progressive progression. In more frequent cases, the course of the disease is secondary progressive, in which the type of relapsing-remitting may develop progressively.

Brain MRI shows non-contrast enhancing lesion which is spread in the cerebrum, thalamus, basal ganglia, and brain stem. Cervical MRI examination shows the same lesion in the cervical segment to the thoracic 3. A positive MRI examination typical of multiple sclerosis followed by a history of similar symptoms previously met the McDonald's diagnosis criteria. McDonald's criteria are outlined in the following table (Table 1). ${ }^{4}$

Management of multiple sclerosis aims to prevent relapse, accelerate recovery, inhibit progression, and overcome symptoms. Commonly used agents are anti-inflammatory and immunomodulatory. The use of anti-inflammatory is based on the inflammatory mechanism that precedes the demyelination process, while the immunomodulator is used to suppress the immune system that plays a role in the autoimmune process. Interferon beta, an immunomodulatory agent commonly used as first-line treatment for multiple sclerosis, may be administered by subcutaneous injection every week or every other day. ${ }^{4,12}$

Interferon is one of the main immunomodulatory agents in the treatment of multiple sclerosis. For 15 years, interferon has been shown to reduce the rate of relapse in secondary progressive multiple sclerosis and reduce disease progression in CIS (clinical isolated syndrome). Based on its molecular structure, interferon could be divided into two types, IFN beta $1 \mathrm{a}$ and $1 \mathrm{~b}$. IFN $1 \mathrm{~b}$ is made from bacterial cells that are unable to do glycosylation which are modified where N-terminal-methionine is removed. Structural stability is maintained by exchanging one cystine group with serine. Unlike IFN $1 \mathrm{~b}$, IFN $1 \mathrm{a}$ is formed from mammalian cells so that it has properties that are more like natural IFN in the body. Due to the differences in these characteristics, IFN 1b is more inactive than IFN 1a, so it requires more and more frequent doses. High immunogenicity increases the risk of neutralizer antibodies that reduce the effectiveness of treatment. ${ }^{13}$

Interferon beta $1 \mathrm{a}$ can be given by injection of intramuscular (Avonex) or subcutaneous (Rebif) three times a week with a dose of $22 \mathrm{mcg}$ or $44 \mathrm{mcg}$. IFN beta $1 \mathrm{~b}$ is given intramuscularly every interval of one day. Interferon has a role as immunomodulatory and antiproliferative. Several studies have shown that interferon can inhibit the development of MS through modulation of the immune system and inflammatory mediators. Interferon beta has four working mechanisms in inhibiting the course of multiple sclerosis diseases. First, IFN can increase upregulation of CD69, type C leptin, which can inhibit spongiosine 1-Phosphate (S1P) receptors, causing reduced lymphocyte migration from the lymph node. Second, IFN can down regulate lymphocyte adhesion molecules (VLA4) and in blood brain barrier (V-CAM) endothelial cells. Decreasing these adhesion molecules will make lymphocyte migration through BBB more difficult. 
Table 1. Revised McDonald's Diagnosis Criteria of Multiple Sclerosis ${ }^{3}$

\begin{tabular}{l}
\hline Clinical Presentation \\
\hline Two or more attacks \\
Two or more objective
\end{tabular}

Two or more obje
clinical lesions

Two or more attacks

One objective clinical lesions

One attack

Two or more objective

clinical lesions

One attack

One objective clinical lesion (clinically isolated syndrome)

Insidious neurological

progression suggestive of MS
Additional Data Needed

None

Dissemination in Space (DIS) can be demonstrated by the presence of 1 or more T2 lesions in at least 2 of 4 of the following areas of the CNS: Periventricular, Juxtacortical, Infratentorial, or Spinal Cord.

Dissemination in Time (DIT), demonstrated by: Simultaneous presence of asymptomatic gadoliniumenhancing and non-enhancing lesions at any time; or A new T2 and/or gadolinium-enhancing lesion(s) on follow-up MRI, irrespective of its timing with reference to a baseline scan; or Await a second clinical attack.

Dissemination in space and time, demonstrated by:

For DIS: 1 or more T2 lesion in at least 2 of 4 MS-typical regions of the CNS (periventricular, juxtacortical, infratentorial, or spinal cord); or Await a second clinical attack implicating a different CNS site.

For DIT: Simultaneous presence of asymptomatic gadolinium-enhancing and nonenhancing lesions at any time; or A new T2 and/or gadolinium-enhancing lesion(s) on follow-up MRI; or Await a second clinical attack.

One year of disease progression and two or three of the following:

1. Evidence for DIS in the brain based on 1 or more T2 lesions in the MS-characteristic

2. Evidence for DIS in the spinal cord based on 2 or more T2 lesions in the cord

3. Positive CSF (isoelectric focusing evidence of oligoclonal bands and/or elevated IgG index)

CNS-Central Nervous System; MRI-Magnetic Resonance Imaging; CSF-Cerebrospinal fluid

Table 2. Immunomudulator used in Multiple Sclerosis ${ }^{17}$

\begin{tabular}{|c|c|c|c|c|}
\hline Agent & Route of Administration & Mechanism of Action & Side effect & $\begin{array}{l}\text { Availability } \\
\text { in Indonesia }\end{array}$ \\
\hline \multicolumn{5}{|c|}{ First Line Treatment } \\
\hline $\begin{array}{l}\text { Dimethyl } \\
\text { Fumarate }\end{array}$ & $\begin{array}{l}\text { Oral capsule } 240 \quad \mathrm{mg} \\
\text { twice daily }\end{array}$ & $\begin{array}{l}\text { Upregulate Nrf2-dependent } \\
\text { antioxidant genes }\end{array}$ & $\begin{array}{l}\text { Flushing, nausea, diarrhea, } \\
\text { abdominal pain, reduce WBC, } \\
\text { elevation AST }\end{array}$ & No \\
\hline Teriflunomide & $\begin{array}{l}\text { Oral tablet } 14 \mathrm{mg} \text { once } \\
\text { daily }\end{array}$ & $\begin{array}{lr}\text { Inhibit } & \text { mitochondrial } \\
\text { enzyme } & \text { dehydrogenase, } \\
\text { reduced } & \text { circulating } \\
\text { lymphocyte } & \end{array}$ & $\begin{array}{l}\text { URTI, UTI, paresthesia, GI } \\
\text { symptom, hair thinning, increase } \\
\text { AST, increase blood pressure }\end{array}$ & No \\
\hline Glatiramer acetate & $\begin{array}{l}\text { Subcutaneous injection } \\
20 \mathrm{mg} \text { once daily }\end{array}$ & $\begin{array}{l}\text { Promoting } \mathrm{Th} 2 \text { to } \mathrm{CD} 4 \mathrm{~T} \\
\text { cell, releasing anti } \\
\text { inflammatory cytokines }\end{array}$ & $\begin{array}{l}\text { Injection site reaction }(65 \%) \text {, facial } \\
\text { flushing, chest tightness, } \\
\text { palpitation, dyspnea }\end{array}$ & No \\
\hline \multicolumn{5}{|c|}{ Second Line Treatment } \\
\hline Natalizumab & $\begin{array}{l}\text { Intravenous infusion } 300 \\
\text { mg every } 4 \text { weeks }\end{array}$ & $\begin{array}{l}\text { Monoclonal antibody } \\
\text { against integrin, preventing } \\
\text { adherencer activated } \\
\text { lymphocyte to endothelium }\end{array}$ & Risk developing PML by JCV virus & No \\
\hline Fingolimod & $\begin{array}{l}\text { Oral capsule } 0.5 \mathrm{mg} \text { once } \\
\text { daily }\end{array}$ & $\begin{array}{l}\text { Sphingosine } \\
\text { 1-phosphater receptor } \\
\text { modulator, degradation } \\
\text { lymphocyte receptor }\end{array}$ & $\begin{array}{l}\text { URTI, headache, cough, diarrhea, } \\
\text { back pain, transient bradycardia and } \\
\text { AV block }\end{array}$ & Yes (Gilenya) \\
\hline Alemtuzumab & $\begin{array}{l}\text { Intravenous infusion } 12 \\
\mathrm{mg} / \text { day for } 5 \text { consecutive } \\
\text { days, followed } 12 \mathrm{mg} / \\
\text { day for } 3 \text { consecutive } \\
\text { days } 12 \text { months later }\end{array}$ & $\begin{array}{l}\text { Monoclonal antibody } \\
\text { against CD52, cytolysis and } \\
\text { complement-mediated lysis }\end{array}$ & $\begin{array}{l}\text { Flushing, nausea, headache, } \\
\text { tachycardia, urticarian, rash, } \\
\text { pruritus, pyrexia, fatigue }\end{array}$ & No \\
\hline Mitoxanthrone & $\begin{array}{l}12 \mathrm{mg} / \mathrm{m}^{2} \text { short IV ( } 5-15 \\
\text { minutes) infusion } \mathrm{q} \\
3 \text { Months } \\
\text { Not to exceed lifetime } \\
\text { cumulative dose of } 140 \\
\mathrm{mg} / \mathrm{m}^{2}\end{array}$ & $\begin{array}{l}\text { Inhibit proliferation; induce } \\
\text { apoptosis of T lymphocytes, } \\
\text { B lymphocytes, } \\
\text { macrophages. }\end{array}$ & $\begin{array}{l}\text { Transient nausea, fatigue, mild hair } \\
\text { loss, menstrual disturbances, UTI, } \\
\text { elevated liver enzyme, leucopenia }\end{array}$ & No \\
\hline
\end{tabular}




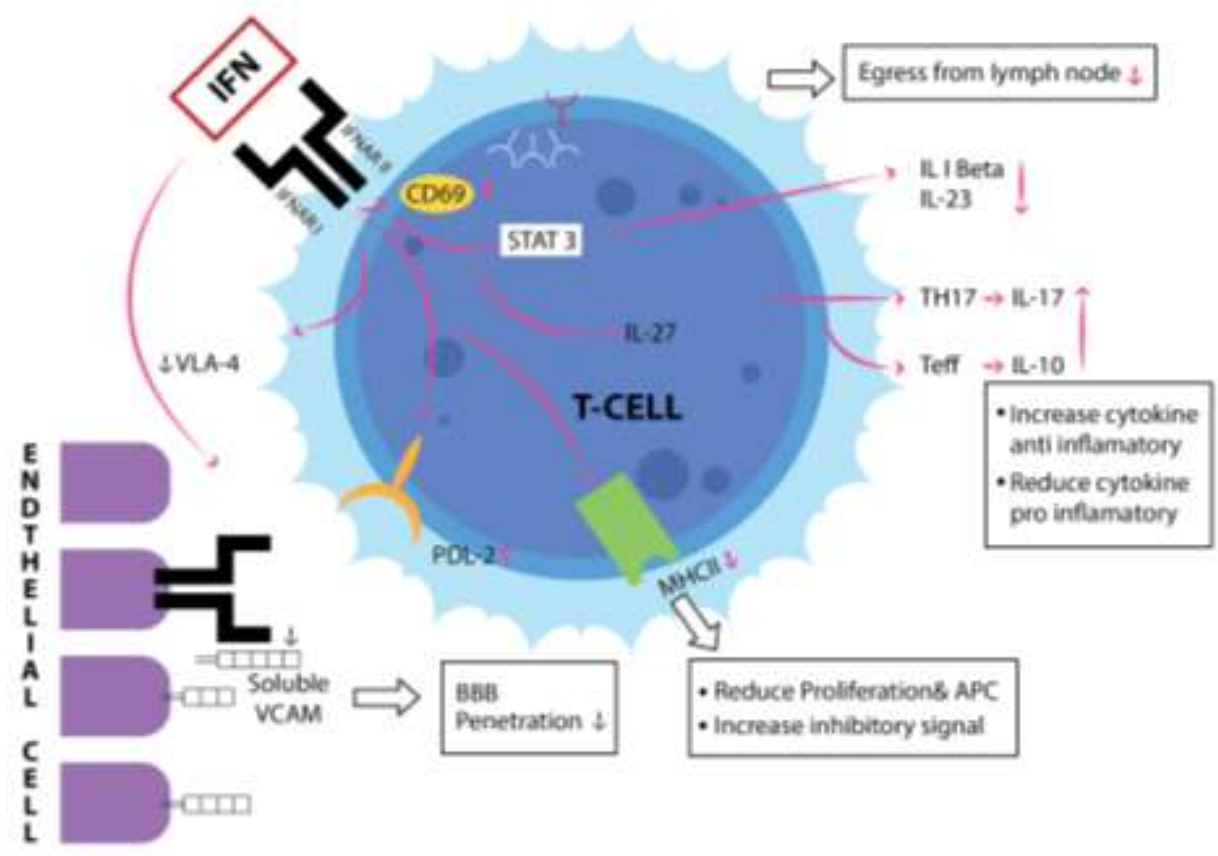

Figure 3. Interferon Mechanism of Action ${ }^{18}$

Third, IFN down regulates MHC, reduce proliferation, and increase PDL-2 which stimulates signal inhibition, and finally IFN modulates differentiation of lymphocyte $T$ cells through the STAT pathway which lowers levels of proinflammatory cytokines such as IL-23 and IL-1, and increases regulation of anti-inflammatory cytokines such as IL-17 and IL-10 (as seen in Figure 3). ${ }^{4,1}$

Based on research conducted by PRISM, the administration of IFN in MS management is generally safe. Side effects that can arise are injection site reaction, malaise, fatigue, depression, headache, flu-like symptoms, and fever. On laboratory examination abnormalities can be found without symptoms, such as increased liver enzymes, leucopenia, lymphophenia, and granulocytopenia. There was no difference in the incidence and severity of side effects in patients treated with doses of $22 \mathrm{mcg}$ or $44 \mathrm{mcg}$.

Laboratory abnormalities generally occur in the first year of treatment and decrease in the second year of treatment. Injection reaction site generally improves in three to four years of treatment. The 4-year follow-up results showed that almost all patients could tolerate side effects and continue treatment. Patients who do not continue treatment generally have complaints of depression and injection site reaction. ${ }^{8}$

In this case the patient experienced a significant remission following each episode of relapse, therefore it was categorized as multiple sclerosis with relapsing-remitting form. The patient has received treatment for 5 years with interferon beta 1a by subcutaneous injection $44 \mathrm{mcg} 3$ times a week. The administration of interferon beta is based on the indications and results of previous studies showing a decrease in the rate of relapse in cases of multiple with relapsing-remitting course. ${ }^{13}$ During the treatment period, the patient has relapsed for 4 times. The occurrence of relapse in the treatment of interferon in multiple sclerosis can be caused by two causes, namely non-compliance and the occurence of neutralizing antibodies. Based on medical information, patients routinely seek treatment during this period so that the possibility of neutralizing antibodies must be considered.

Neutralizer antibodies (NAb) is the main obstacle in interferon administration as multiple sclerosis therapy. Just like other human recombinant proteins, beta interferon has immunogenic properties that can trigger antibodies. Factors for the appearance of antibodies are influenced by the structure and molecular stability of interferon, the frequency and dose of administration, and the patient's immune status. Antibodies generally appear more frequently in IFN beta $1 \mathrm{~b}$ due to cell structures derived from bacterial cells and molecular differences with human cells. Positive NAB is less common in patients with a dose of $44 \mathrm{mcg}$ IFN treatment, but the effect on the amount of relapse is greater than treatment with a dose of $22 \mathrm{mcg}$. The $\mathrm{NAb}$ appears more frequently in patients given a $22 \mathrm{mcg}$ IFN dose three times a week, generally appearing in the first 18 months, also NAb occurs more frequently in subcutaneous injection compared with intramuscular injection. In people with impaired immune status, such as cancer patients, antibodies appear more frequently than patients with stable immune status. ${ }^{8,13}$

Based on research conducted by the 18-month PRISM trial, $\mathrm{NAb}$ did not show changes in the effectiveness of interferon therapy. However, observations over 4 years showed patients with positive NAb more often relapsed than patients with negative NAb. On a positive MRI examination on NAb there was a wider presence of T2 active lesions. Patients with positive NAb also have higher risk to developed disability compared to negative NAb patients. $^{13}$

Neutralizing antibodies can be detected by various examinations, such as the Kawade titration method, cytopathic effect (CPE) assay, and MxA induction. ${ }^{14}$ The 
Kawade titration method measures the quantity of antibodies with a cut off of $20 \mathrm{NU} / \mathrm{ml}$. The CPE examination method measures the ability of $\mathrm{NAb}$ in the patient's serum to neutralize the ability of IFN in cells infected with the virus. MxA induction measures the ability of NAb to reduce IFN markers gene, both at mRNA level or protein level. From the various examinations, the IFN marker examination is the best sensitivity test. Besides MxA induction, other IFN markers that can be used are neopterin and beta- 2 microglobulin. In cases where the NAb titer was more than 20, a significant decrease in levels of beta-2 microglobulin and neopterin was found. Examination of MxA induction in vitro with NAb titer levels below $150 \mathrm{TRU} / \mathrm{ml}$ showed IFN bioactivity in the normal stage, titers of 150-600 TRU/ml IFN bioactivity was reduced, and titers of more than $600 \mathrm{TRU} / \mathrm{ml}$ IFN ability disappeared completely. ${ }^{13,15}$

Positive NAB status is still a debate whether it is permanent or not, because in some cases NAb can disappear spontaneously, and in some cases can continue to persist even if IFN is stopped. Spontaneous loss of NAb is generally more common in patients given IFN beta $1 \mathrm{~b}$ than IFN beta 1a s.c. In patients with positive NAb, $50 \%$ of cases will be negative NAb in 4 years, followed by the return of normal bioactivity from IFN. Changes to negative $\mathrm{NAb}$ are more common in patients with low NAb titers ( $<100 \mathrm{NU} / \mathrm{ml}) .15 \mathrm{It}$ is still not known exactly the method of converting positive NAB into negative. One explanation is that generally $\mathrm{NAb}$ is more common in giving high protein levels (IFN beta $1 \mathrm{~b}$ ) which breaks down immune tolerance, then giving proteins with the same level will restore immune tolerance status. It was proved by administering IFN beta $1 \mathrm{~b}$ which reduces NAb levels. Research conducted by Petersen showed that the longest period of positive NAb to negative change was 59 months. In some cases, NAb remains positive even though therapy has been replaced or IFN is terminated. One possibility is the presence of long-lived plasma cells, another possibility is the presence of cross reactions with natural beta IFN antibodies in the body, so that antibodies will continue to form when there is stimulation of IFN, such as viral infection. $^{16}$

Neutralizing antibodies generally appear before 24 months of administration, therefore NAb screening is recommended in the 12th and 24th months, if the results are negative then the NAb examination is performed when the relapse episode occurs. In patients with positive NAb, further management is carried out based on NAb titers. At very high NAb titers (> $500 \mathrm{NU} / \mathrm{ml}$ ) interferon administration is recommended to be stopped and replaced with other immunomodulatory therapies because the continued administration does not show beneficial results and increases costs. In low or medium NAb titers, discontinuation of treatment is still a debate because in one third of cases there is still normal IFN bioactivity, a third of cases decrease in partial IFN bioactivity, and one third of cases of total IFN reduction. Therefore it is recommended that in vivo examination with $\mathrm{MxA}$ induction. If with $\mathrm{MxA}$ induction the IFN response is absent, a change of therapy is recommended. ${ }^{13,15-16}$

In this case, neutralizing antibodies were not carried out in vivo or in vitro due to limited facilities and infrastructure.
Suggestions from experts suggest that if possible the examination is carried out abroad or other means that provide the examination. If a neutralizing antibodies titer of more than $500 \mathrm{NU} / \mathrm{ml}$ or an IFN response drops or even is absent from MxA induction, it is recommended that treatment be stopped and replaced with another immunomodulator.

In cases where alternating interferon therapy is highly recommended, other immunomodulators can be considered as listed in the table $2 .^{17}$

The recommended replacement therapy is non-interferon therapy, both from the first line and second line, such as glatiramer acetate, teriflunomid, dimethyl fumarate, natalizumab, fingolimod, alemtuzumab, and mithoxanthrone. In this case the recommended agent is fingolimod because this is the only agent which is available in Indonesia. The Phase III RRMS trial showed that fingolimod given $0.5 \mathrm{mg}$ once a day, compared with placebo, showed a decrease in relapse rates of $48-55 \%$, disabilitic progression of $25-30 \%$, and MRI lesions of $80 \% .^{16}$ Common side effects are upper respiratory tract infections, coughing, diarrhea and pains. A more serious side effect is transient bradycardia to AV block, therefore the use of fingolimod must be reconsidered in patients with arrhythmia. Cardiovascular monitors are recommended for the first 6 hours of dosing, and long-term monitoring in patients with arrhythmia or taking drugs that can trigger bradycardia. Laboratory tests of liver enzymes and eye examinations were carried out after 3 months of treatment due to increased cardiac enzymes and macular edema. ${ }^{1}$

\section{Conclusion}

Multiple sclerosis is an incurable autoimmune disease with various symptoms and challenging treatment. In Indonesia, limited treatment option for relapsing remitting type of MS including disease modyfying drugs such as interferon beta, which is not only effective in improving symptoms, but also in reducing the attack frequency and slowing disease progressivity. In cases with suspicion of interferon resistance, biomarker testing of drug specific antibodies such as Kawade titration method, cytopathic effect (CPE) assay, and MxA induction should be performed to gain valuable and further evaluation.

\section{Acknowledgment}

The authors would like to thank the patient, dr. Vinson Hartoyo, dr. Pamela Tiffani, Department of Neurology Faculty of Medicine Universitas Pelita Harapan, and Siloam Hospitals Lippo Village for facilitating this case report study.

\section{References}

1. Langer-Gould A, Brara SM, Beaber BE, Zhang JL. Incidence of multiple sclerosis in multiple racial and ethnic groups. Neurology; 2013. 80(19);1734-9. DOI: $10.1212 /$ WNL.0b013e3182918cc2

2. Cheong WL, Mohan D, Warren N, Reidpath DD. Multiple sclerosis in the asia pacific region: A systematic review of a neglected neurological disease. 
Front Neurol; 2018. 9(432);1-9.

DOI: $10.3389 /$ fneur.2018.00432

3. Polman $\mathrm{CH}$, Reingold SC, Banwell B, Clanet M, Cohen JA, Fillippi M, et al. Diagnostic criteria for multiple sclerosis; 2010 revisions to the McDonald criteria. Ann Neural. 2011. 69(2);292-302.

DOI: 10.1002/ana.22366

4. Ropper AH, Brown RH. Adam and Victor's Principle of Neurology, $10^{\text {th }}$ ed. China: McGraw-Hill; 2014

5. Boz C, Oger J, Gibbs E, Grossberg SE. Reduced effectiveness of long-term interferon -beta treatment on relapses in neutralizing antibosy-positive multiple sclerosis patients: a Canadian sclerosis clinic-based study. Mult Scler; 2007. 13(9); 1127-37. DOI: 10.1177/1352458507080468

6. Tomassini V, Paolillo A, Russo P, Giugni E, Prosperini L, Gasperini C, et al. Predictors of long-term clinical response to interferon beta therapy in relapsing multiple sclerosis. J Neurol; 2006. 253(3);287-93.

DOI: $10.1007 / \mathrm{s} 00415-005-0979-5$

7. Sorensen PS. Neutralizing antibodies againts interferon-beta. Therapeutic Advances in Neurological Disorders; 2008. 1(2);124-41.

DOI: $10.1177 / 1756285608095144$

8. Browne P, Chandraratna D, Thompson AJ. Atlas of multiple sclerosis 2013: A growing global problem with widespread inequity. Neurology; 2014. 83(11);1022-1024.

DOI: $10.1212 /$ WNL.0000000000000768

9. Wilkins A. Cerebellar dysfunction in multiple sclerosis. Front Neurol; 2017. 8(312);1-6.

DOI: 10.3389/fneur.2017.00312

10. Lucchinetti CF, Popescu BF, Bunyan RF, Moll NM, Roemar SF, Lassmann H, et al. Inflammatory cortical demyelination in early multiple sclerosis. N Eng J Med; 2011. 365;2188-97.
DOI: $10.1056 /$ NEJMoa1 100648

11. Moroso A, Ruet A, Deloire M, Lamargue-Hamel D, Cubizolle S, Charré- Morin J, et al. Cerebellar assessment in early multiple sclerosis. Cerebellum; 2017. 16(2);607-11. DOI: 10.1007/s12311-016-0831-8

12. Chong HT, Tan CT. Review of multiple sclerosis with asian perspectives. Med J Malaysia; 2008. 63(5);35661.

Available from: https://www.ncbi.nlm.nih.gov/pubmed/19803290

13. Manfredonia F, Pasquali L, Dardano A, Iudice A, Murri L, Monzani F. Review of the clinical evidence for interferon beta $1 \mathrm{a}$ in the treatment of multiple sclerosis. Neuropsychiatric Disease and Treatment; 2008. 4(2);321-36. DOI: 10.2147/ndt.s476

14. Bermel RA, Rudick RA. Interferon-beta treatment for multiple sclerosis. Neurotherapeutics; 2007. 4(4);63346. DOI: 0.1016/j.nurt.2007.07.001

15. Deisenhammer F, Schellekens H, Bertolotto A. Measurement of neutralizing antibodies to interferon beta in patients with multiple sclerosis. J Neurol; 2004. 251(2);31-9. DOI: 10.1007/s00415-004-1206-5

16. Namaka M, Pollitt-Smith M, Gupta A, Klowak M, Vasconcelos M, Turcotte D, et al. The clinical importance of neutralizing antibodies in relapsingremitting multiple sclerosis. Curr Med Res Opin; 2006. 22(2);223-39. DOI: 10.1185/030079906X80413

17. Torkildsen O, Myhr KM, Bo L. Disease Modifying Treatment for Multiple Sclerosis - A Review of Approved Medications. European Journal of Neurology; 2015. 23(1);18-27. DOI: $10.1111 /$ ene. 12883

18. Kieseier BC. The mechanism of action of interferon- $\beta$ in relapsing multiple sclerosis. CNS Drugs; 2011. 25(6):491-502. DOI: 10.2165/11591110-00000000000000 . 